\title{
Effect of micro-encapsulated n-3 fatty acids on quality properties of two types of dry sausages
}

\author{
Zdeněk Pavlík ${ }^{1}$, Alena Saláková ${ }^{1}, J_{0}$ ef Kameník ${ }^{1}$, Jan Pospíšil², Michaela Králová \\ Iva Steinhauserová ${ }^{1}$
}

University of Veterinary and Pharmaceutical Sciences Brno, Faculty of Veterinary Hygiene and Ecology, ${ }^{1}$ Department of Meat Hygiene and Technology, ${ }^{2}$ Department of Milk Hygiene and Technology, Brno, Czech Republic

Received June 25, 2013

Accepted January 23, 2014

\begin{abstract}
Dry sausages are popular traditional meat products. As these products are a rich source of animal fat, there is an effort to improve their fatty acid ratio. The aim of this work was to study the effect of micro-encapsulated n-3 fatty acids added into dry sausages. Samples of dry sausages (Poličan and Vysočina) enriched with unsaturated fatty acids ( $36 \mathrm{~g}$ for $6 \mathrm{~kg}$ of mixture) and rosemary extract $\left(0.3 \mathrm{~g} \cdot \mathrm{kg}^{-1}\right)$ were made along with control samples. Physicochemical, instrumental analyses were performed, fatty acid profile was measured by gas chromatography, and oxidation processes were monitored by determination of thiobarbituric acid reactive substances. No significant differences $(P \geq 0.05)$ in quality indicators were found between samples, however, there were differences in oxidation processes. Sausages enriched with unsaturated fatty acids showed an increase in thiobarbituric acid reactive substances $\left(>2 \mathrm{mg} \cdot \mathrm{kg}^{-1}\right.$ and $>3 \mathrm{mg} \cdot \mathrm{kg}^{-1}$ in Poličan and Vysočina, respectively, compared to control). Sausages enriched with unsaturated fatty acids and also with rosemary extract have the similar concentration of thiobarbituric acid reactive substances as the control. An increase in the proportion of monounsaturated fatty acids and polyunsaturated fatty acids was seen in samples of Poličan supplemented with unsaturated fatty acids in combination with rosemary extract. The addition of rosemary extract had also a significant effect in increasing the proportion of unsaturated fatty acids in samples of Vysočina. From the viewpoint of quality indicators, changes in the properties of the product were not seen in any samples.
\end{abstract}

Dry fermented sausage, linseed oil, rosemary extract, TBARS

Dry meat products are extremely popular among consumers in the Czech Republic. However, these traditional meat products display certain negative aspects as a consequence of their high animal fat content. Polyunsaturated fatty acids of the n-3 series are now recognised as a dietary factor that is beneficial to health and tends to reduce the risk of many illnesses, particularly atherosclerosis and other cardiovascular diseases (Connor 2000). Two main strategies are used to increase the polyunsaturated fatty acids (PUFA) ratio in meat products. Several works have focused on enriching raw materials by feeding animals a diet rich in $\alpha$-linolenic acid (Sheard et al. 2000; Hoz et al. 2004). Other experiments have increased the PUFA fraction by substituting pork back fat with seed oils, which has proved to be a good way of improving their nutritional properties (García-Íñiguez de Ciriano et al. 2010a). The propensity of polyunsaturated fatty acids to oxidise limits their usefulness in foods and necessitates the development of new strategies and technological procedures to protect against oxidation. Various strategies can be adopted to minimise oxidation, either by limiting contact with oxygen and/or by using antioxidants. GarcíaÍñiguez de Ciriano et al. (2010b) showed that it is possible to develop new meat products rich in polyunsaturated fatty acids and ensure their protection from oxidation by natural or synthetic antioxidants. The antioxidant qualities of certain types of herbs and spices have been well known and documented for quite some time (Haak et al. 2009). The natural 
antioxidant mentioned most frequently in connection with meat products is rosemary. The effectiveness of these extracts has been tested in various foods, including sunflower oil, fish oil, the meat of fish, chicken and turkey, as well as in pork and beef. The ability of these extracts to retard the oxidation of lipids in meat during storage has been proven many times over (Keokamnerd et al. 2008).

The aim of this study was to optimise the composition of dry sausages by adding fatty acids of the n-3 series, and to determine if a natural antioxidant (rosemary extract) is suitable to protect them against oxidation.

\section{Materials and Methods}

Two types of traditional Czech meat products were prepared: the dry fermented sausage known as Poličan and the hot smoked dry sausage known as Vysočina. Sausages were divided into four groups. The group of control samples was produced following the traditional recipe. The batch of meat mixture of all samples was 6 $\mathrm{kg}$ (10 samples), containing $2 \mathrm{~kg}$ of lean pork meat, $2 \mathrm{~kg}$ of beef and $2 \mathrm{~kg}$ of pork back fat. The second group of sausages was enriched with a preparation (PRO CORDE ALA ORGANIC, GAT Food Essentials, Ebenfurth, Austria) containing unsaturated fatty acids in micro-encapsulated form derived from linseed oil. One-hundred $\mathrm{g}$ of preparation contained the following fatty acids: $3-5.5 \mathrm{~g}$ oleic acid (n-9), 3-5.5 g linoleic acid (n-6) and 12-15.5 $\mathrm{g} \alpha$-linolenic acid (ALA). The dosage was $36 \mathrm{~g}$ of preparation per $6 \mathrm{~kg}$ of meat mixture. Third group of sausages was enriched with the same preparation plus a rosemary extract $\left(0.3 \mathrm{~g} \cdot \mathrm{kg}^{-1}\right)$ as a natural antioxidant. The fourth group of sausages was enriched only with the rosemary extract.

Samples were analysed during ripening, at the end of ripening, and after 4 weeks of vacuum-packed cold $\left(3.0 \pm 0.5^{\circ} \mathrm{C}\right)$ storage on days $0,7,14,21$, and 49 . The following indicators were subsequently determined: dry matter content, fat content, chlorides, collagen and protein content; the variables were measured according to Válková et al. (2007). The degree of lipid oxidation (content of thiobarbituric acid reactive substances TBARS) was measured by a reaction with thiobarbituric acid after distillation according to Castellini et al. (2002). Water activity was measured with a Novasina LabMaster instrument (Novasina AG, Switzerland) and pH measurements using a Double Pore needle probe (Hamilton Bonaduz AG, Switzerland) and a 340i WTW pHmeter (WTW, Germany). Samples were tested by texture profile analysis (TPA) using an Instron universal testing machine (model 5544) (Instron Corporation, USA). Cylinder samples ( $2 \mathrm{~cm}$ in height, $2.5 \mathrm{~cm}$ in diameter) were compressed twice to $50 \%$ of their original height with a compression platen $36 \mathrm{~mm}$ in diameter (Szczesniak 2002).

Colour was measured by the CIE L*a*b* system using a Minolta CM 2600d (Konica Minolta, Japan). A measuring area of $3 \mathrm{~mm}$, illuminant D65 and $10^{\circ}$ standard observer were used. The instrument was standardised using a standard white plate: CIE $\mathrm{L}^{*}$ - lightness, $\mathrm{a}^{*}$ - redness, and $\mathrm{b}^{*}$ - yellowness.

Methanol esterification method using potassium hydroxide catalysis was chosen for preparing samples of fatty acids (CSN EN ISO 5509, 2001). Fatty acid profiles were determined as fatty acid methyl esters (FAMEs) by gas chromatography (GC) (Agilent, USA) with a flame ionisation detector. The samples containing FAMEs in $\mathrm{n}$-hexane were transferred to a GC vial and $1 \mathrm{ml}$ was injected into the GC. Analysis was performed with a VB-WAX column $(60 \mathrm{~m} \times 0.32 \mathrm{~mm}$ i.d.) with a film thickness of $0.25 \mu \mathrm{m}$ (VICI and ValcoBond, USA). The injector temperature was $280{ }^{\circ} \mathrm{C}$ and the detector temperature was $300{ }^{\circ} \mathrm{C}$. The initial temperature of $50{ }^{\circ} \mathrm{C}$ was maintained for $8 \mathrm{~min}$, then raised to $220^{\circ} \mathrm{C}$ at a rate of $10{ }^{\circ} \mathrm{C} / \mathrm{min}$, maintained for $20 \mathrm{~min}$, and then increased to $240{ }^{\circ} \mathrm{C}$ at a rate of $5^{\circ} \mathrm{C} / \mathrm{min}$ for $30 \mathrm{~min}$. A split was used (split ratio 12:1) and nitrogen was the carrier gas. The period of the analysis was $79 \mathrm{~min}$. The data measured were processed using Clarity Software (DataApex, CZ). Standard FAME Mix 37 (Supelco, USA) was used for identification and quantification.

Statistical data analyses were conducted using the statistical program STATISTICA CZ version 7 (StatSoft, Prague, Czech Republic). ANOVA was used for determination of variability among the groups of samples. Significance levels of $0.05,0.01$ and 0.001 were used.

\section{Results}

The results of basic chemical testing performed on the meat products Poličan and Vysočina are listed in Table 1 and Table 2, respectively. The $\mathrm{pH}$ values of all samples (Poličan sausages) were consistent with the character of the products, though significant differences $(P \leq 0.05)$ were recorded between the samples in dependence on the addition of unsaturated fatty acids and also in dependence on the concurrent addition of antioxidant. Water activity was $<0.90$ and $0.91-0.92$ in all Poličan and Vysočina samples, respectively. The indicators (fat content and pure muscle protein) did not differ significantly $(P \geq 0.05)$ in any samples. 
Table 1. Results of physicochemical and instrumental analysis of the dry fermented sausage Poličan at the end of ripening (21 days).

\begin{tabular}{lcccc}
\hline \multirow{2}{*}{ Indicators } & Control & \multicolumn{3}{c}{ Sausages with supplement } \\
\cline { 2 - 5 } & & $\mathrm{n}-3$ fatty acids & $\mathrm{n}-3+$ rosemary extract & Rosemary extract \\
\hline $\mathrm{pH}$ & $4.600 \pm 0.005$ & $4.565 \pm 0.005$ & $4.484 \pm 0.005$ & $4.559 \pm 0.006$ \\
$\mathrm{a}_{\mathrm{w}}$ & $0.895 \pm 0.002$ & $0.884 \pm 0.002$ & $0.881 \pm 0.000$ & $0.898 \pm 0.001$ \\
Fat (\%) & $43.56 \pm 2.40$ & $42.35 \pm 0.41$ & $39.45 \pm 1.59$ & $43.26 \pm 0.91$ \\
$\mathrm{TBARS}\left(\mathrm{mg} \cdot \mathrm{kg}^{-1}\right)$ & $2.26 \pm 0.11$ & $4.29 \pm 0.11$ & $2.78 \pm 0.21$ & $2.36 \pm 0.02$ \\
$\mathrm{NaCl}(\%)$ & $3.89 \pm 0.01$ & $3.88 \pm 0.18$ & $3.91 \pm 0.10$ & $3.78 \pm 0.08$ \\
$\mathrm{PMP}(\%)$ & $18.59 \pm 0.58$ & $17.25 \pm 0.08$ & $18.50 \pm 1.19$ & $17.22 \pm 0.46$ \\
$\mathrm{Hardness}(\mathrm{N})$ & $97.13 \pm 8.99$ & $92.40 \pm 7.52$ & $92.70 \pm 7.72$ & $97.83 \pm 8.81$ \\
$\mathrm{~L}^{*}$ & $43.85 \pm 1.28$ & $42.20 \pm 1.23$ & $41.76 \pm 0.59$ & $42.69 \pm 2.34$ \\
$\mathrm{a}^{*}$ & $14.23 \pm 1.77$ & $14.27 \pm 0.88$ & $14.12 \pm 0.72$ & $14.52 \pm 1.30$ \\
$\mathrm{~b}^{*}$ & $10.50 \pm 1.68$ & $10.10 \pm 0.46$ & $10.35 \pm 1.67$ & $10.91 \pm 1.80$ \\
\hline
\end{tabular}

$\mathrm{a}_{\mathrm{w}}$ - water activity, TBARS - thiobarbituric acid reactive substances, PMP - pure muscle proteins, $\mathrm{L}^{*}-$ lightness, $\mathrm{a}^{*}$ - redness, $\mathrm{b}^{*}$ - yellowness.

Results are presented as mean \pm standard deviation.

Table 2. Results of physicochemical and instrumental analysis of the hot smoked dry sausage Vysočina samples at the end of ripening (21 days).

\begin{tabular}{lcccc}
\hline \multirow{2}{*}{ Indicators } & Control & \multicolumn{3}{c}{ Sausages with supplement } \\
\cline { 2 - 4 } & & $\mathrm{n}$-3 fatty acids & $\mathrm{n}$-3 + rosemary extract & Rosemary extract \\
\hline $\mathrm{pH}$ & $5.390 \pm 0.053$ & $5.573 \pm 0.027$ & $5.466 \pm 0.072$ & $5.536 \pm 0.030$ \\
$\mathrm{a}_{\mathrm{w}}$ & $0.918 \pm 0.001$ & $0.920 \pm 0.002$ & $0.912 \pm 0.003$ & $0.917 \pm 0.002$ \\
Fat (\%) & $41.87 \pm 0.20$ & $42.04 \pm 1.36$ & $40.05 \pm 1.40$ & $40.14 \pm 0.04$ \\
TBARS (mg.kg-1) & $0.60 \pm 0.06$ & $3.81 \pm 0.27$ & $1.74 \pm 0.01$ & $2.02 \pm 0.01$ \\
$\mathrm{NaCl}(\%)$ & $3.85 \pm 0.12$ & $3.82 \pm 0.02$ & $3.71 \pm 0.14$ & $3.85 \pm 0.16$ \\
PMP (\%) & $17.98 \pm 0.40$ & $16.94 \pm 0.31$ & $18.64 \pm 1.32$ & $18.21 \pm 0.33$ \\
Hardness (N) & $42.11 \pm 8.47$ & $41.03 \pm 3.49$ & $39.96 \pm 8.81$ & $39.99 \pm 8.90$ \\
L* & $43.94 \pm 3.72$ & $49.28 \pm 0.26$ & $43.44 \pm 2.55$ & $40.93 \pm 0.19$ \\
$\mathrm{a}^{*}$ & $15.10 \pm 1.53$ & $16.69 \pm 0.41$ & $15.92 \pm 0.75$ & $15.70 \pm 0.81$ \\
$\mathrm{~b}^{*}$ & $11.22 \pm 0.80$ & $13.40 \pm 0.79$ & $10.40 \pm 0.56$ & $10.13 \pm 0.42$ \\
\hline
\end{tabular}

$\mathrm{a}_{\mathrm{w}}$ - water activity, TBARS - thiobarbituric acid reactive substances, PMP - pure muscle proteins, $\mathrm{L}^{*}-$ lightness, $\mathrm{a}^{*}$ - redness, $\mathrm{b}^{*}$ - yellowness.

Results are presented as mean \pm standard deviation

The TBARS content in Poličan and Vysočina during the manufacturing process and storage of these products is shown in Fig. 1 and Fig. 2, respectively. The content of TBARS in the sausage mixture was several times higher in the samples enriched with n-3 fatty acids than in the control.

The addition of unsaturated fatty acids influenced the texture of Poličan sausage. These differences were significant; the samples had softer texture compared to control $(P \leq$ 0.05 ) or to the samples with the addition of antioxidant alone. There were no significant differences in the texture of Vysočina sausages. Differences were found in the colour of certain samples in terms of lightness and proportion of red and yellow colours. The samples of Vysočina sausage enriched with unsaturated fatty acids displayed higher values 


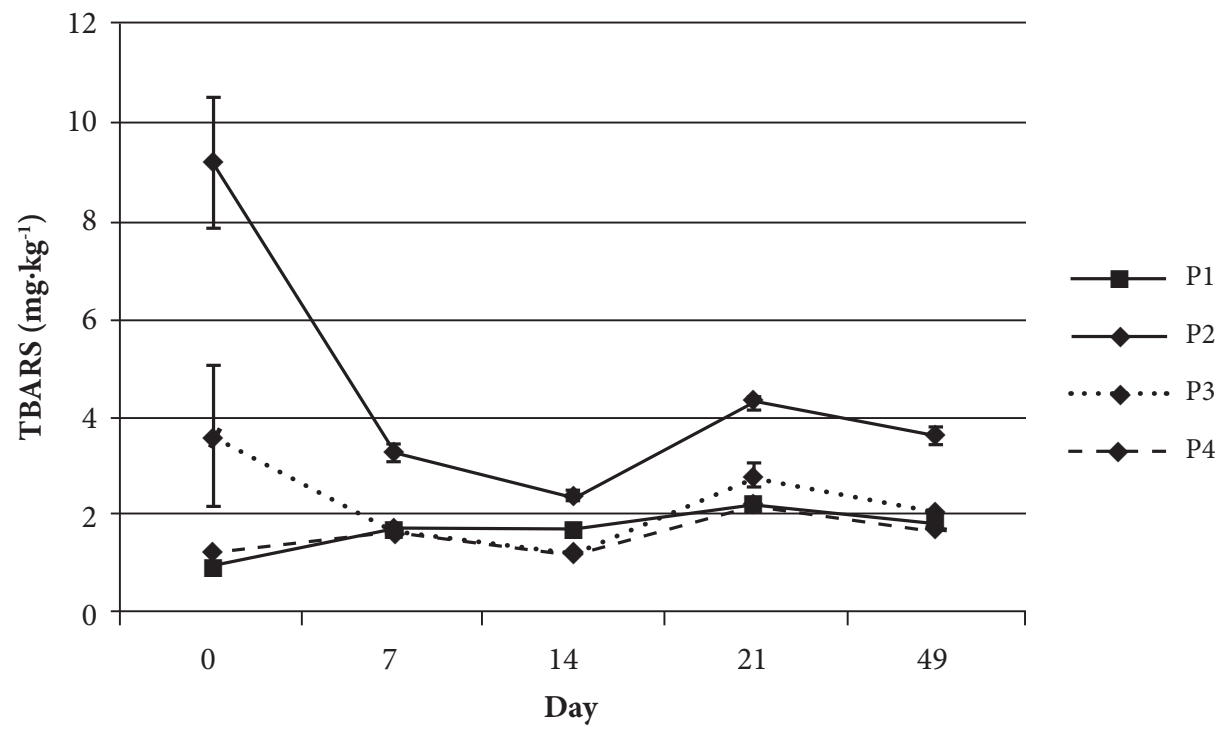

Fig. 1. Progression of oxidation changes in dry fermented sausage Poličan

P1 - control, P2 - sample with the addition of n-3 fatty acids, P3 - sample with the addition of n-3 fatty acids and a natural antioxidant (rosemary extract), P4 - sample with the addition of a natural antioxidant (rosemary extract), TBARS - thiobarbituric acid reactive substances

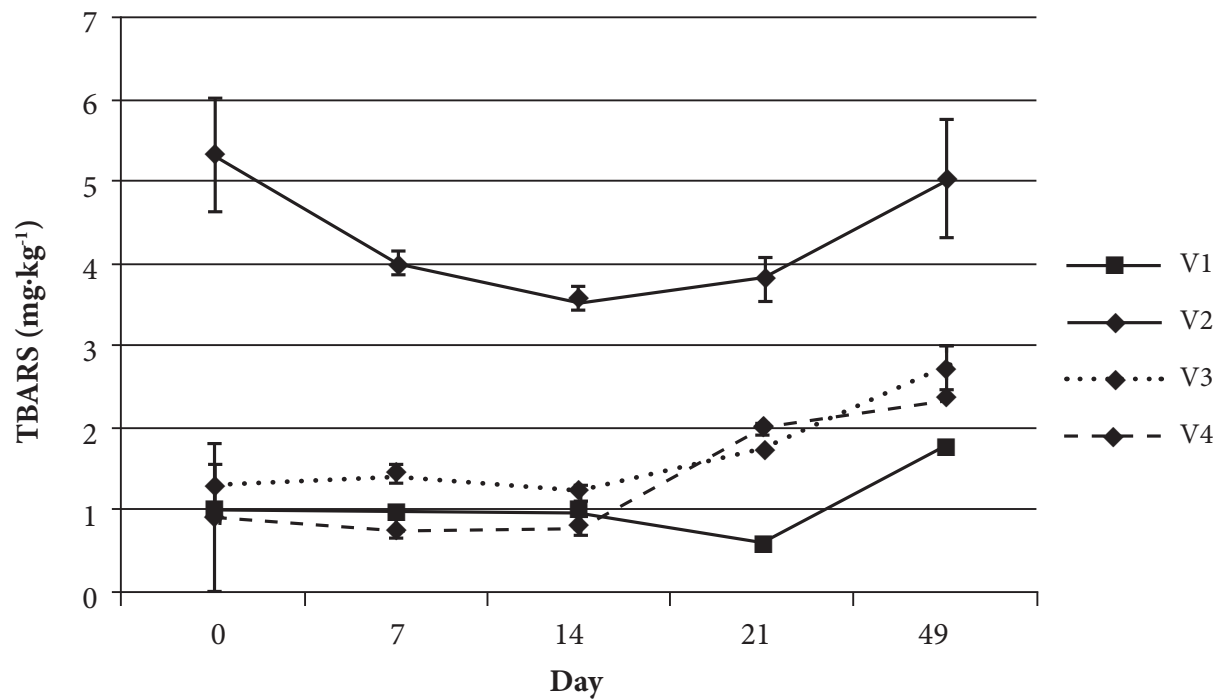

Fig. 2. Progression of oxidation changes in dry nonfermented sausage Vysočina

V1 - control, V2 - sample with the addition of n-3 fatty acids, V3 - sample with the addition of n-3 fatty acids and a natural antioxidant (rosemary extract), V4 - sample with the addition of a natural antioxidant (rosemary extract), TBARS - thiobarbituric acid reactive substances 
Table 3. Ratio of fatty acids in dry Poličan and Vysočina sausages at the end of ripening (21 days).

\begin{tabular}{lcccc}
\hline & \multicolumn{4}{c}{ Poličan sausage } \\
& Control & $\mathrm{n}-3$ & $\mathrm{n}-3+$ rosemary extract & Rosemary extract \\
\hline SFA (\%) & 65.15 & 65.10 & 50.10 & 58.85 \\
MUFA (\%) & 31.55 & 31.10 & 43.55 & 39.75 \\
PUFA (\%) & 3.05 & 3.70 & 6.70 & 1.20 \\
n-6/n-3 & 9.17 & 6.40 & 8.00 & 13.10 \\
& \multicolumn{4}{c}{ Vysočina sausage } \\
& Control & $\mathrm{n}-3$ & $\mathrm{n}-3+$ rosemary extract & Rosemary extract \\
SFA (\%) & 63.30 & 56.60 & 55.40 & 52.40 \\
MUFA (\%) & 35.20 & 39.35 & 40.70 & 42.80 \\
PUFA (\%) & 1.20 & 4.25 & 4.20 & 4.90 \\
n-6/n-3 & 11.00 & 7.50 & 9.50 & 13.00 \\
\hline
\end{tabular}

SFA - saturated fatty acids, MUFA - monounsaturated fatty acids, PUFA - polyunsaturated fatty acids

for all colour indicators compared to the other samples $(P \leq 0.05)$; there were no significant differences in colour indicators of Poličan sausages.

Table 3 shows the proportions of fatty acids in the individual samples. No significant increase $(P \geq 0.05)$ in the percentage proportion of MUFA was seen in samples of Poličan sausage following the addition of unsaturated fatty acids. The proportion of PUFA increased slightly in these samples, and there was also a reduction in the ratio of n-6/n-3 unsaturated acids. A significant increase $(P \leq 0.05)$ in the proportion of MUFA was seen only following the addition of rosemary extract, along with an increase in the values of PUFA as more than twice the original levels.

\section{Discussion}

Lipid modification of meat products by replacing animal fat with other lipid sources has proved to be good strategy for improving the nutritional quality and achieving the desired biochemical effects without ingestion of supplements or changes in dietary habits (Triki et al. 2013). These reformulated products require proper control of quality indicators. We proceeded with our products with an added polyunsaturated fatty acid preparation in a similar manner.

In our study, the $\mathrm{pH}$ values of the samples were lower than those of the control samples. A similar reduction was noted in the past in products in which vegetable oil was substituted for part of the fat for the purpose of increasing the amount of unsaturated fatty acids (Muguerza et al. 2002). In certain cases, this reduction was so great that the resultant value no longer corresponded to the requirements for the given product (Yildiz-Turp and Serdaroglu 2008). In our study, the indicators of contents of fat and pure muscle protein in meat samples did not differ significantly, similarly as in the study of García-Íñiguez de Ciriano et al. (2010b). The water activity in meat samples from our study met the requirements of the Czech legislation (No. 326/2001). Values of water activity in Vysočina samples were lower compared to previous results (Procházková et al. 2010).

One of the potential problems deriving from fat formulations of the healthier meat product is an acceleration of the oxidative process with implications for quality and health (Triki et al. 2013). In our study, significant differences were found in the quantity of TBARS. Higher values in the samples enriched with n-3 fatty acids could be because of 
a relatively high degree of oxidation in the infused preparation containing n-3 fatty acids, which cannot be avoided even by strict compliance with storage conditions. In the first week of the manufacturing process, we found a depletion of TBARS in these samples, so that their level fall considerably. However, compared to the other samples, they still remained substantially higher during the entire manufacturing process, even after storage of the final product for a period of one month. The samples enriched with the natural antioxidant in addition to the n-3 fatty acids also exhibited a significant decline in the content of TBARS, which was already evident in the sausage mixture. The onset of the antioxidant effect occurred, therefore, in an extremely short period of time, practically during the mixing and filling operations. Over the next 7 days, the values of TBARS in these samples dropped to a level closely approximating the values detected in the controls. In the Poličan samples, this level remained consistent throughout the manufacturing process, even after a month of storage (similarly to the findings of García-Íñiguez de Ciriano et al. [2010b] for this type of product), while a mild increase of TBARS was registered in the final product of Vysočina samples. When a preparation containing unsaturated fatty acids is used, the addition of antioxidants is decisive in controlling auto-oxidation, in contrast to the enrichment of the product with unsaturated fatty acids by substituting vegetable oil (which is protected against oxidation by its own natural antioxidants) for lard (Muguerza et al. 2001, 2003). Conversely, the samples treated only with the natural antioxidant did not exhibit an appreciable decline in the TBARS content relative to the controls in any of the products.

The proportion of PUFA increased slightly in samples with the addition of a preparation with unsaturated fatty acids, and there was also a reduction to the ratio of $n-6 / n-3$ unsaturated acids. However, such a pronounced fall in the n-6/n-3 ratio was not detected, as an increase in the proportion of all PUFA led to a higher increase in the values of n-6 fatty acids. Other authors have recorded a more pronounced fall in the $n-6 / n-3$ ratio (Valencia et al. 2006; García-Íñiguez de Ciriano et al. 2010b). The addition of rosemary extract to a sample that was not enriched with unsaturated fatty acids meant a slight increase in the proportion of MUFA but no increase in the quantity of PUFA, for which lower values were measured. In samples of Vysočina sausage, an increase in the proportion of MUFA and PUFA and a slight fall in the ratio of $n-6 / n-3$ unsaturated acids occurred following the addition of a preparation of unsaturated fatty acids. An even more pronounced increase in the values of MUFA and PUFA occurred following the addition of rosemary extract itself. In contrast, however, the $n-6 / n-3$ ratio increased slightly in this case.

This experiment studied the effect of the addition of unsaturated fatty acids and natural antioxidants on quality indicators and nutritional properties in dry meat products. An increase in the proportion of MUFA and PUFA was seen in samples of Poličan sausage. The addition of rosemary extract had a more significant effect in increasing the proportion of MUFA and PUFA in samples of Vysočina sausage than direct enrichment with unsaturated fatty acids. From the viewpoint of quality indicators, changes in the properties of the product were not seen in any of the samples, and all the products satisfied the demands of the national legislation.

\section{Acknowledgement}

The study received financial support from Project IGA VFU Brno 84/2011/FVHE.

\section{References}

326/2001 Czech notification as amended of Ministry of agricultural (in Czech) 2001: part 126, p. 7414

Castellini C, Mugnai C, Dal Bosco A 2002: Effect of organic production system on broiler carcass and meat quality. Meat Sci 60: 219-225

Connor WE 2000: Importance of n-3 fatty acids in health and disease. Am J Clin Nut 71: 171- 175 
CSN EN ISO 5509 2001: Animal and vegetable fats and oils - preparing of methyl esters of fatty acids. Czech office for standards, metrology and testing, $40 \mathrm{p}$.

García-Íñiguez de Ciriano M, Rehecho S, Calvo MI, Cavero RY, Navarro I, Astiasarán I, Ansorena D 2010a: Effect of lyophilized water extracts of Melissa officinalis on the stability of algae and linseed oil-in-water emulsion to be used as a functional ingredient in meat products. Meat Sci 85: 373-377

García-Íñiguez de Ciriano M, Larequi E, Rehecho S, Calvo MI, Cavero RY, Navarro-Blasco I, Astiasarán I, Ansorena D 2010b: Selenium, iodine, $\Omega-3$ PUFA and natural antioxidant from Melissa officinalis L.: A combination of components from healthier dry fermented sausages formulation. Meat Sci 85: 274-279

Haak L, Raes K, De Smet S 2009: Effect of plant phenolics, tocopherol and ascorbic acid on oxidative stability of pork patties. J Sci Food Agricult 89: 1360-1365

Hoz L, D’Arrigo M, Cambero I, Ordónez JA 2004: Development of an n-3 fatty acid and a-tocopherol enriched dry fermented sausage. Meat Sci 67: 485-495

Keokamnerd T, Acton JC, Han IY, Dawson PL 2008: Effect of commercial rosemary oleoresin preparations on ground chicken thigh meat quality packaged in a high-oxygen atmosphere. Poultry Sci 87: 170-179

Muguerza E, Fista G, Ansorena D, Astiasarán I, Bloukas JG 2002: Effect of fat level and partial replacement of pork backfat with olive oil on processing and quality characteristics of fermented sausages. Meat Sci 61: 397-404

Muguerza E, Gimeno O, Ansorena D, Bloukas JG, Astiasarán I 2001: Effect of replacing pork backfat with pre-emulsified olive oil on lipid fraction and sensory quality of Chorizo de Pamplona-a traditional Spanish fermented sausage. Meat Sci 59: 251-258

Muguerza E, Ansorena D, Astiasarán I 2003: Improvement of nutritional properties of Chorizo de Pamplona by partial replacement of pork backfat with soy oil. Meat Sci 65: 1361-1367

Procházková Z, Dračková M, Saláková A, Gallas L, Pospiech M, Vorlová L, Tremlová B, Buchtová H 2010: Application of FT NIR spectroscopy in the determination of basic physical and chemical properties of sausages. Acta Vet Brno 79: 101-106

Sheard PR, Enser M, Wood JD, Nute GR, Gill BP, Richardson RI 2000: Shelf life and quality of pork and pork products with raised n-3 PUFA. Meat Sci 55: 213-221

Szczesniak AS 2002: Texture is sensory property. Food Qual Pref 13: 215-225

Triki M, Herrero AM, Rodríguez-Salas L, Jiménez-Colmenero F, Ruiz-Capillas C 2013: Chilled storage characteristics of low-fat, n-3 PUFA-enriched dry fermented sausage reformulated with a healthy oil combination stabilized in a konjac matrix. Food Cont 31: 158-165

Valencia I, Ansorena D, Astiasarán I 2006: Nutritional and sensory properties of dry fermented sausages enriched with n-3 PUFAs. Meat Sci 72: 727-733

Válková V, Saláková A, Buchtová H, Tremlová B 2007: Chemical, instrumental and sensory characteristics of cooked pork ham. Meat Sci 77: 608-615

Yildiz-Turp G, Serdaroglu M 2008: Effect of replacing beef fat with hazelnut oil on quality characteristics of sucuk - A Turkish fermented sausage. Meat Sci 78: 447-454 